\title{
desenvolvimento QUESTÂOO
}

\section{DIMENSÕES DA SUSTENTABILIDADE NOS ORÇAMENTOS MUNICIPAIS DA REGIÃO METROPOLITANA DO VALE DO PARAÍBA E LITORAL NORTE - SP}

http://dx.doi.org/10.21527/2237-6453.2021.56.11069

Recebido em: $5 / 7 / 2020$

Aceito em: 6/5/2021

\author{
Luiz Rodolfo França Pinheiro, ${ }^{1}$ Mônica Franchi Carniello, ${ }^{2}$ \\ Edson Aparecida de Araujo Querido Oliveira, ${ }^{2}$ Adriana Leonidas de Oliveira ${ }^{2}$
}

\begin{abstract}
RESUMO
A abordagem sustentável dos orçamentos municipais mostra a realidade social, econômica e ambiental da governança pública. Destarte, esta pesquisa objetivou analisar as execuções orçamentárias municipais da Região Metropolitana do Vale do Paraíba e Litoral Norte (RMVPLN)-SP, identificando as despesas pagas direcionadas às Dimensões Social, Econômica e Ambiental (Triple Bottom Line - TBL). Assim, realizou-se uma pesquisa documental, relativa a 2019, no Portal da Transparência de cada município e do Tribunal de Contas do Estado de São Paulo. Os resultados mostraram uma grande disparidade nos índices das despesas pagas tanto internamente nas dimensões quanto na comparação das médias entre elas (social: 57,57\%; econômica: 12,26\%; e ambiental: 2,36\%). No resultado agregado das dimensões TBL da sustentabilidade, as cidades de Jambeiro, Redenção da Serra e Piquete apareceram como representantes dos maiores somatórios percentuais de recursos alocados nas dimensões TBL; por outro lado, São José dos Campos, Jacareí e Pindamonhangaba figuraram entre as com menores somatórios percentuais. Por fim, as correlações apontaram que conforme aumentam os indicadores PIB, IFDM e População, diminuem as despesas pagas na RMVPLN com a sustentabilidade agregada. Conclui-se pela importância do planejamento e execução orçamentária municipal pelos gestores públicos, seja na equalização melhor da aplicação das despesas entre as dimensões TBL, seja realizando uma publicidade mais eficiente e eficaz desses gastos. Finalmente, recomendam-se análises futuras para se gerar uma série histórica.
\end{abstract}

Palavras-chave: gestão pública; RMVPLN; Triple Bottom Line (TBL).

DIMENSIONS OF SUSTAINABILITY IN MUNICIPAL BUDGETS IN THE METROPOLITAN REGION OF PARAÍBA VALLEY AND NORTH COAST - SP

\begin{abstract}
The sustainable approach to municipal budgets shows the social, economic and environmental reality of public governance. Thus, this research aimed to analyze the municipal budget executions of the Metropolitan Region of Paraíba Valley and SP North Coast (RMVPLN), identifying expenses paid to the Social, Economic and Environmental Dimensions (Triple Bottom Line - TBL). Thus, a documentary research, relative to 2019, was carried out on the Transparency Portal of each municipality and the São Paulo State Audit Court. The results showed a great disparity in the indices of expenses paid both internally in the dimensions and in the comparison of the averages between them (social: 57.57\%; economic: $12.26 \%$; and environmental: $2.36 \%$ ). In the aggregate result of the TBL dimensions of sustainability, the cities of Jambeiro, Redenção da Serra and Piquete appeared as representatives of the highest percentage of resources allocated in the TBL dimensions; on the other hand, São José dos Campos, Jacareí and Pindamonhangaba were among those with the lowest percentage sums. Finally, the correlations pointed out that as the GDP, IFDM and Population indicators increase, the expenses paid at RMVPLN with aggregate sustainability decrease. It concludes by the importance of municipal budget planning and execution by public managers, either in better equalizing the application of expenses between the TBL dimensions, or by making more efficient and effective advertising of these expenses. Finally, future analyzes are recommended to generate a historical series.
\end{abstract}

Keywords: public management; RMVPLN; Triple Bottom Line (TBL).

\footnotetext{
${ }^{1}$ Autor correspondente. Exército Brasileiro - Centro de Instrução de Aviação do Exército. Estrada Municipal dos Remédios - Granjas Rurais Reunidas São Judas Tadeu. Taubaté/SP, Brasil. CEP 12086-000. luizrodolfofp72@gmail.com

2 Universidade de Taubaté (Unitau). Taubaté/SP, Brasil.
} 


\section{INTRODUÇÃO}

Sustentabilidade é um termo que merece atenção de todas as organizações, sejam elas do setor privado ou público, pois por meio da adoção de seus princípios podem ser minimizados desperdícios, obtidos maiores ganhos e entregues produtos aos consumidores ainda melhores e a preços mais competitivos. O foco permanece no alinhamento das ações entre as partes interessadas, tanto as endógenas quanto as exógenas (AGRAWALA; SINGHB, 2019).

Além do foco nas ações com os stakeholders (partes interessadas), outro deve estar direcionado ao equilíbrio entre as dimensões social, econômica e ambiental da sustentabilidade. Sachs (1988, p. 160) alerta que "o social e o ecológico emergem como principais preocupações diante da devastação provocada pela hegemonia incontrolável do econômico e da primazia da lógica de mercado sobre a lógica das necessidades". Nota-se a importância do balanceamento entre as dimensões do desenvolvimento sustentável e as exigências do mercado.

Não existe uma maneira única de se atingir o desenvolvimento econômico, seja ele pelas vias convencionais (que não levam em conta a sustentabilidade - quase um suicídio organizacional nos dias atuais) ou pelas vias do desenvolvimento econômico sustentável ou Triple Bottom Line (TBL), conceito cunhado por John Elkington, em 1994, e difundido em seu livro "Cannibals with forks: the triple bottom line of 21st century business", em 1997, termo que representou a expansão dos tradicionais modelos de negócios - que só considerava fatores econômicos na avaliação de uma empresa - para novos modelos, que passam a considerar além da financeira, também a performance ambiental e social (WISE, 2016).

O TBL é atingido quando as organizações buscam prosperidade econômica, qualidade ambiental e justiça social em suas metas e em seus negócios. Essas três linhas estão inter-relacionadas, interdependentes e parcialmente em conflito, pois dependem de uma revolução de pensamento e atuação em várias direções, tais como mercados, valores, transparência, tecnologia do ciclo de vida, parcerias, perspectiva de tempo e governança corporativa (JEURISSEN, 2000; WISE, 2016).

Na busca do desenvolvimento econômico por meio do TBL há de se manter os objetivos principais de vitalidade econômica, administração de recursos e bem-estar da comunidade de maneira única e comum, embora os meios para atingir esses objetivos variem com fatores contextuais, como tipo de projeto, recursos da comunidade e escala. Mais significativamente, 0 desenvolvimento econômico do TBL exige novas formas de contabilizar o impacto e uma compreensão mais sutil das interações entre fatores econômicos, ambientais e sociais (HAMMER; PIVO, 2017). Essa percepção sutil os gestores públicos precisam desenvolver para proporcionarem aos municípios geridos uma administração que retorne à população produtos e serviços de qualidade.

A Lei $\mathrm{n} 010.257$, de 10 de julho de 2001, editada para regulamentar o comando constitucional previsto nos artigos 182 e 183 da Constituição Federal e estabelecer as diretrizes gerais da política urbana brasileira (Estatuto da Cidade), tratando da sustentabilidade TBL, traz aos gestores públicos uma série de orientações que se alinham ao tema quando pede garantia do direito aos munícipes de cidades sustentáveis (moradias dignas, saneamento ambiental, infraestrutura urbana, transporte, serviços públicos) e de atenção a um planejamento no desenvolvimento municipal que leve em conta a distribuição espacial da população e as atividades 
econômicas do município e do território, com a intenção de se evitar e/ou corrigir distorções do crescimento econômico (BRASIL, 2001).

Com esses apontamentos iniciais, percebe-se a relevância do estudo da sustentabilidade e de suas dimensões social, econômica e ambiental com um olhar voltado às atuações dos gestores públicos em relação aos orçamentos municipais, pois os princípios orçamentários previstos no Manual Técnico de Orçamento 2020 (BRASIL, 2020), que conferem racionalidade, eficiência e transparência aos processos de elaboração, execução e controle do orçamento público para todas as esferas de governo, devem ser seguidos à risca também pelos administradores públicos municipais (BRASIL, 2020).

Ademais, estudos anteriores na mesma direção abordam somente indicadores e/ou índices da RMVPLN e suas relações entre si (PINHEIRO; VIEIRA; OLIVEIRA, 2019; FUZARO; CARNIELLO, 2020), deixando uma lacuna quanto ao comportamento desses indicadores em relação às destinações orçamentárias para a sustentabilidade TBL na região.

Assim, diante dessa lacuna, da importância do tema e do desconhecimento de informações relevantes referentes a quanto os municípios da Região Metropolitana do Vale do Paraíba e Litoral Norte (RMVPLN) destinam em seus orçamentos para as dimensões TBL da sustentabilidade, esta pesquisa teve como objetivo analisar a execução dos orçamentos municipais da RMVPLN quanto às dimensões da sustentabilidade (TBL).

Por fim, este artigo apresenta-se em cinco seções: introdução; referencial teórico, na qual serão abordados os temas do desenvolvimento sustentável e de suas dimensões (TBL) e dos instrumentos orçamentários municipais; método, detalhando os instrumentos de intervenção; resultados e discussões, seção na qual serão apresentados os dados das despesas pagas nos orçamentos municipais da RMVPLN direcionados às dimensões da sustentabilidade e, por fim, conclusão.

\section{REFERENCIAL TEÓRICO}

\section{Desenvolvimento sustentável e suas dimensões social, econômica e ambiental (TBL)}

O desenvolvimento sustentável é o imperativo atual do rearranjo estrutural do sistema econômico e, consequentemente, a competitividade muito mais acirrada entre os países do mundo está correlacionada com o crescimento econômico, com a modernização da economia e da sociedade, mas, sobretudo, com os indicadores socioeconômicos do desenvolvimento sustentável (DALEVSKA et al., 2019), o que coloca às organizações uma necessidade de se modernizarem e de sobreviverem no atual ambiente político-econômico-social (DALLABRIDA, 2011).

Normalmente, as empresas líderes do mercado já adotam em seus planejamentos essa abordagem sustentável, contudo tal adaptação deve ser difundida e disseminada a todas as empresas, como alerta Dallabrida (2011, p. 288), que defende que "para sobreviverem, as empresas precisariam adaptar-se continuamente ao meio socioeconômico em função das inovações tecnológicas adotadas pelas empresas líderes".

Essa articulação de grandes empresas com pequenas e microempresas situadas ao longo de toda a cadeia produtiva também é abordada por Sachs (2010) sob a ótica do desenvolvimento sustentável, o qual o autor nomeia como "desenvolvimento includente". E nessa perspectiva 
de criar sinergias positivas nessas interfaces organizacionais (grandes $\mathrm{x}$ pequenas e microempresas), com mais transparência e controle social, o autor declara que "é nessa direção que tento trabalhar hoje no Brasil, na tripla perspectiva do desenvolvimento socialmente includente, ecologicamente viável e economicamente sustentado" (SACHS, 2010, p. 36).

Além das empresas já constituídas, Gu et. al. (2021) defendem que os gestores públicos devem estar cientes de que o empreendedorismo é uma possível solução para o desafio do desenvolvimento sustentável, devendo todas as esferas de governo incentivarem o empreendedorismo, a proteção de patentes, as tecnologias verdes e os programas de educação voltados à inovação. Além disso, os gestores públicos devem exercer seu papel moderador tanto no empreendedorismo quanto na regulamentação da inovação, com o intuito de reduzir os danos ambientais (GU et. al., 2021).

Esse mesmo enfoque no empreendedorismo sustentável, Sargani et al. (2020) trazem quando argumentam que a atividade empreendedora só pode ser rotulada como sustentável e, portanto, como uma ação que satisfaz o desenvolvimento sustentável, se houver uma abordagem igualitária e distributiva na combinação do social, do econômico e do ambiental. A sustentabilidade, portanto, está no cerne do empreendedorismo sustentável e, assim sendo, exige que o empresário genuinamente sustentável seja aquele que abre uma empresa com foco em aspectos do TBL (SARGANI et al., 2020).

Assim, a adoção do desenvolvimento sustentável em todas as organizações e empresas poderia ser um caminho para se vencer a questão do "mau desenvolvimento" abordado por Sachs (1998, p. 150) quando alerta que "enquanto um bilhão de habitantes de nosso planeta vive em prosperidade, outro bilhão sobrevive numa miséria que desafia qualquer descrição e quatro bilhões dispõem de rendas modestas próximas do mínimo vital. O fenômeno marcante do século é, portanto, o mau desenvolvimento". Dessa forma, a sustentabilidade ofereceria não só às organizações melhores resultados, como esses resultados também poderiam resgatar a dignidade desses bilhões de pessoas citadas por Sachs.

Dallabrida também aborda a concepção de desenvolvimento como muito mais ampla do que somente crescimento e sob várias dimensões sustentáveis quando trata da sua relação com cultura e economia, argumentando que "não só há uma relação entre economia, cultura e desenvolvimento [...] como são elementos constitutivos dos processos de desenvolvimento, somados às dimensões social, política, espacial, ecológica e tecnológica" (DALLABRIDA, 2011, p. 297). Dentre todas essas dimensões, destacam-se as três que formam a "linha tripla de fundo" (TBL) ou, o também chamado "tripé da sustentabilidade": dimensões social, econômica e ambiental.

Essa abordagem do TBL da sustentabilidade, apesar de ser complexa e requerer uma perspectiva temporal diferente dos modelos de gerenciamento tradicionais, permite um planejamento mais longo, juntamente com uma maior tolerância à incerteza e uma maior capacidade de aprender com o passado, o que leva a um aumento da inovação sustentável e fornece melhorias ambientais e sociais e, ainda, mitiga possíveis impactos negativos no desempenho econômico das organizações. Essa visão holística da ética sustentável nos negócios, envolvendo as questões TBL, é um passo importante que as organizações podem dar em suas gestões (LONGONI; CAGLIANO, 2016).

Ainda no setor público, as estratégias e diretrizes do TBL seguem as mesmas do setor privado e sempre deveriam ter em vista metas de longo prazo, mas tomadas no tempo presente, como enfatiza Wise (2016) ao dizer que "as estratégias regenerativas do setor público e do setor 
privado, de acordo com o quadro do TBL, enfatizam as metas de longo prazo, no entanto os resultados avaliados e as consequências futuras dependem das decisões atuais" (WISE, 2016). Infelizmente, como na maioria das vezes a questão política interfere nos planejamentos, a visão de longo prazo nem sempre é colocada em prática com decisões atuais acertadas, por exemplo, com os mecanismos orçamentários municipais.

\section{Instrumentos orçamentários municipais: Planejamento Plurianual, Lei de Diretrizes Orçamentárias e Lei Orçamentária Anual}

A seriedade e o equilíbrio que os gestores devem ter na condução dos orçamentos municipais deve se pautar no que o IBGC $(2015$, p. 13) traz ao destacar que "está cada vez mais em evidência a responsabilidade dos diferentes agentes de governança diante de temas como sustentabilidade, corrupção, [...] além da complexidade e multiplicidade de relacionamentos que as organizações estabelecem com os mais variados públicos". Sendo assim, os instrumentos orçamentários são balizas importantes aos gestores públicos no que diz respeito à condução do dinheiro comum municipal.

O Plano Plurianual (PPA) municipal é um instrumento de planejamento orçamentário elaborado pelo poder Executivo municipal, mas aprovado pelo Legislativo da cidade, e tem a abrangência de quatro anos consecutivos, com sua vigência iniciando-se no segundo ano do mandato do prefeito, interferindo, por consequência, no primeiro ano do mandato do próximo mandatário. O PPA estabelece diretrizes, objetivos e metas da administração pública municipal para as despesas de capital e outras delas decorrentes, prevendo receitas que financiarão as metas propostas e evitando aquelas impossíveis de serem alcançadas em apenas quatro anos.

Além do mais, o PPA deve interligar as diretrizes e os objetivos do Plano Diretor municipal, que consiste no instrumento básico de planejamento e política de desenvolvimento e expansão urbana municipal e que contém os aspectos físicos, sociais, econômicos e sociais para obtenção de uma melhor qualidade de vida para a população (CEPAM, 2005), com o Estatuto da Cidade. Assim, o PPA proporciona uma visão daquilo que o governo se propõe a realizar em médio prazo, e cuja realização está vinculada à utilização de recursos orçamentários (CEPAM, 2005).

A Lei de Diretrizes Orçamentárias (LDO), prevista na Constituição Federal brasileira, orienta a elaboração da Lei Orçamentária Anual (LOA) para que esta expresse metas e prioridades da administração pública, disponha sobre alterações na legislação tributária e estabeleça a política de aplicação das agências financeiras oficiais de fomento (BRASIL, 2020). Na esfera municipal, a LDO é uma lei proposta também pelo Executivo, com vigência anual, constituindo um instrumento "de planejamento orçamentário que compreende as metas e prioridades da administração pública municipal, incluindo as despesas de capital para o exercício financeiro subsequente, orientando a elaboração da LOA e dispondo sobre as alterações na legislação tributária" (CEPAM, 2005, p. 54).

Ainda em relação à LDO, em 2000, a Lei de Responsabilidade Fiscal (LRF), Lei Complementar $n$ ㅇ 101, de 4 de maio de 2000, criada com o intuito principal de condicionar os gastos à arrecadação de tributos, designou novas atribuições para a LDO, associadas, em grande medida, à responsabilidade da gestão fiscal, obrigando esta lei a dispor sobre o equilíbrio entre receitas e despesas; os critérios e forma de limitação de empenho, normas relativas ao controle de custos e à avaliação dos resultados dos programas financiados com recursos do orçamento, entre outros (BRASIL, 2020). 
Por fim, a Lei Orçamentária Anual (LOA) municipal, também de iniciativa do Executivo municipal, é a lei que estima as receitas e fixa as despesas para um determinado exercício financeiro e tem vigência de um ano (CEPAM, 2005). No tocante às despesas fixadas na LOA, Cepam (2005, p. 58) explicita que "são destinadas à manutenção e conservação dos serviços já existentes e à criação, expansão e aprimoramento da ação governamental, com base nas diretrizes, objetivos e metas aprovadas no PPA e na LDO [...]".

Dessa forma, é importante entender como as despesas previstas nesses documentos orçamentários (PPA, LDO E LOA) são administradas nos municípios dessa importante região metropolitana do Estado de São Paulo e do Brasil, a RMVPLN, um dos principais eixos de desenvolvimento do Estado de São Paulo (OLIVEIRA; QUINTAIROS, 2011), criada no ano de 2012 pela Lei Complementar no 1.166-SP, de 9 de janeiro de 2012 (SÃO PAULO, 2012).

\section{MÉTODO}

A RMVPLN possui 39 municípios (listados na Tabela 1), divididos em cinco sub-regiões, e concentra mais de 2,5 milhões de habitantes (segundo estimativa do IBGE para 2018), gerando $4,8 \%$ do Produto Interno Bruto (PIB) paulista em 2016. Esta Região está situada entre as principais metrópoles do país, São Paulo e Rio de Janeiro, e possui seus principais municípios localizados às margens da rodovia Presidente Dutra (OLIVEIRA; QUINTAIROS, 2011).

Desenvolveu-se uma pesquisa descritiva por meio do detalhamento dos dados levantados na análise e interpretação das informações dos orçamentos municipais relativas às dimensões da sustentabilidade TBL (SILVA; MENEZES, 2005).

No que diz respeito aos resultados, a investigação caracterizou-se como do tipo básica, pois objetivou "gerar conhecimentos novos úteis para o avanço da ciência sem aplicação prática 'prevista'”' (SILVA; MENEZES, 2005, p. 20).

Utilizou-se de uma pesquisa documental no Portal da Transparência de cada município da RMVPLN e no Portal da Transparência do Tribunal de Contas do Estado de São Paulo (TCESP, 2020), no período de 14 a 30 de abril de 2020. Para Prodanov e Freitas (2013), fontes documentais podem ser quaisquer registros passíveis de uso como fonte de informação, que tenham sido investigados e que tenham passado pelos crivos da observação, leitura e reflexão críticas quanto ao processo e conteúdo, além de terem sido examinados quanto ao valor do material utilizado para o trabalho.

Esta pesquisa analisou as informações das despesas pagas pelos 39 municípios da RMVPLN, na execução orçamentária 2019 e relativas às dimensões da sustentabilidade TBL, levando em consideração a classificação das despesas conforme adotadas no Quadro 1.

Quadro 1 - Classificação e Distribuição das Despesas Pagas por Dimensão TBL na RMVPLN em 2019

\begin{tabular}{|c|c|c|c|}
\hline \multicolumn{4}{|c|}{ Dimensões TBL } \\
\hline \multicolumn{2}{|c|}{ Social } & Econômica & Ambiental \\
\hline Inclusão (Assistência) Social & Saúde & Turismo & Gestão Ambiental \\
Desporte/Lazer & Educação & Urbanismo (transporte) & Saneamento \\
Segurança & Cultura & Desenvolvimento (Indústria) & \\
\hline
\end{tabular}

Fonte: Dados da Pesquisa (2021). 
Na busca dos dados do Quadro 1, públicos e disponíveis a todos os cidadãos no Portal da Transparência dos 39 municípios da RMVPLN (listados na Tabela 1), verificou-se que as cidades utilizavam-se de várias empresas contratadas para administrar seus sites (mais de 7 tipos diferentes), as quais também realizavam a divulgação das informações orçamentárias. A grande maioria das cidades trabalhava com duas empresas que possuíam as interfaces de mais fácil manipulação, tanto para o acesso quanto para a exportação dos dados públicos para um computador particular, pois se utilizavam de arquivos com extensão 'cvs' que abriam, facilmente, como planilha 'xls' no Excel.

Alguns municípios, contudo, apresentaram dificuldades no acesso, por exemplo, Campos do Jordão, que não tinha as informações completas e não possuía plataforma para exportar dados diretos para manipulação; Caraguatatuba e São Bento do Sapucaí, que só possuíam planilhas em 'pdf'; Jacareí, cujo Portal da Transparência não abria; Lagoinha e São Luiz do Paraitinga, que não possuíam todos os meses de 2019; e São José dos Campos e Ubatuba, que não possuíam um demonstrativo anual consolidado. Para todos esses municípios com problemas no acesso às informações, foi necessário acessar o site do TCESP (2020) e baixar o arquivo "despesa detalhada" do ano de 2019, com o qual se realizou a separação das informações referentes às despesas pagas por cada município (por secretaria e/ou função e subfunção) direcionadas às dimensões TBL.

Após a obtenção de todas as informações das despesas pagas por cada município em cada dimensão TBL na moeda nacional (real), usou-se da equação a seguir para se chegar ao percentual aplicado pelos municípios em relação a cada dimensão. Optou-se por trabalhar com percentuais em vez dos valores nominais, pelo motivo de que os percentuais representam meIhor quanto verdadeiramente uma cidade aplica em cada dimensão, tendo em vista a grande disparidade nos valores dos orçamentos da RMVPLN. Os percentuais encontram-se explicitados na Tabela 1.

$\mathrm{D}-\mathrm{TBL}(\%)=\sum$ despesas pagas relacionadas à dimensão $(\mathrm{R} \$) /$ Despesa Total do ano $(\mathrm{R} \$)$, onde:

$\mathrm{D}-\mathrm{TBL}=$ dimensão $\mathrm{TBL}$ com suas respectivas despesas relacionadas pelo Quadro $1 \mathrm{em} \%$; e

Despesa Total do ano $=$ despesa total empenhada consolidada no município em RȘ, TCESP (2020).

Com esses percentuais, utilizou-se da metodologia da divisão em quintis para classificar e pontuar cada município em todas as dimensões TBL, dividindo-se o conjunto de dados em cinco partes proporcionais. Neste trabalho utilizou-se do software Excel para essas divisões por meio da equação 'percentil.exc(matriz;0,2)', 'percentil.exc(matriz;0,4)', sucessivamente. Com essas operações, definiram-se as separatrizes de cada parte (dos $20 \%$ inferiores, assim por diante). Essa metodologia foi utilizada por Gomes e Vieira (2018) em um trabalho voltado também à sustentabilidade na RMVPLN.

Desta maneira, usou-se de pontuações de 1 a 5 , sendo 1 a pior pontuação e 5 a melhor. Com a classificação em cada dimensão TBL, realizou-se uma análise quantitativa para se verificar o comportamento de cada dimensão TBL em separado diante dos índices PIB, IFDM e População dos Municípios. Utilizaram-se previamente os testes de normalidade e posteriormente os testes de correlação, por meio do software SPSS. 
O Teste de Normalidade utilizado foi o de Shapiro-Wilk, que é um dos testes usados para amostras menores que 50 unidades, o que é o caso em toda a análise, tendo em vista serem 39 municípios na RMVPLN. Field (2009), na abordagem sobre o Teste de Shapiro-Wilk, esclarece que este teste é usado para amostras pequenas, pois "é afetado por amostras grandes nas quais pequenos desvios da normalidade geram resultados significativos" (p. 658).

Testada a normalidade das relações, utilizou-se dos testes de correlação para saber qual o relacionamento existente entre as variáveis estudadas, conforme se pode ver em Field (2009, p. 125) que destaca que "correlação é uma medida do relacionamento linear entre variáveis".

Neste estudo utilizaram-se as correlações de Pearson, também chamado de coeficiente de correlação momento produto de Pearson, quando os dados apresentam-se com distribuição normal (dados paramétricos); e de Spearman, que é uma medida padronizada da força do relacionamento entre duas variáveis e utilizada quando os dados não apresentam distribuição normal (dados não paramétricos) (FIELD, 2009).

Tanto as correlações de Pearson quanto a de Spearman podem apresentar resultados com valores que vão de -1 a +1 , sendo que para Field $(2009$, p. 129) "o coeficiente de correlação é uma medida do tamanho de um efeito comumente utilizada: valores de $\pm 0,1$ representam um efeito pequeno, $\pm 0,3$ representa um efeito médio e $\pm 0,5$, um efeito grande".

Tanto os testes de normalidade quanto as correlações são análises técnicas nas quais segundo Creswell (2007, p. 35), um pesquisador "usa primariamente alegações pós-positivistas para desenvolvimento de conhecimento [...] e emprega estratégias de investigação (como experimentos, levantamentos e coleta de dados, instrumentos predeterminados que geram dados estatísticos)". Na mesma linha, Santos, Oliveira e Morais (2010, p. 24), trazem que "nessa abordagem, o valor intrínseco à pesquisa refere-se à possibilidade de mensuração dos fatos, eventos ou variáveis correlacionadas".

Após a classificação em cada dimensão TBL, gerou-se um resultado agregado de todas as pontuações e voltou-se a classificar as cidades por meio de nova divisão de quintis. Assim, ao final dessa metodologia, chegou-se a cinco grupos distintos e classificados de altamente sustentáveis, representantes dos maiores somatórios percentuais de recursos alocados nas dimensões TBL, a insustentáveis, os menores somatórios.

Com o resultado agregado da sustentabilidade TBL, novamente realizou-se uma abordagem quantitativa para se verificar o comportamento do resultado agregado TBL diante dos índices PIB, ao IFDM e à População dos Municípios, por meio do software SPSS.

O Produto Interno Bruto (PIB), segundo Oliveira (2018), ainda é o principal indicador mundial do nível da atividade econômica de um país, região ou município, sendo o total de bens e serviços produzidos em um determinado período. Já o IFDM (Índice Firjan de Desenvolvimento Municipal) é uma metodologia desenvolvida pela Firjan, e avalia as áreas da saúde, educação e emprego e renda de um município. Seus indicadores variam de 0 a 1 (sendo 1 o melhor desempenho), distribuídos em 4 faixas de desenvolvimento: baixo $(0,0$ a 0,4$)$, regular $(0,4$ a 0,6$)$, moderado $(0,6$ a 0,8$)$ e alto $(0,8$ a 1$)$ (GOMES; VIEIRA, 2018).

Cabe ressaltar que este trabalho restringiu-se aos orçamentos relativos ao ano de 2019 e somente aos das prefeituras, excluindo-se os das Câmaras Municipais e outras empresas públicas ou fundações. 


\section{RESULTADOS E DISCUSSÃO}

De posse dos dados das despesas pagas nos orçamentos dos 39 municípios da RMVPLN e seguindo a metodologia explicada no método, chegou-se a um importante resultado deste trabalho, demonstrado na coluna "Despesas com as Dimensões da Sustentabilidade 2019" da Tabela 1, que é quanto cada cidade do Vale do Paraíba e do Litoral Norte de São Paulo gasta com as dimensões social, econômica e ambiental, percentualmente.

Ademais, a Tabela 1 também traz os seguintes indicadores dos 39 municípios da RMVPLN, que serão utilizados para as correlações com o resultado agregado TBL: IFDM 2018 (ano base 2016), variando de 0,61 - moderado (São Luiz do Paraitinga) ao índice 0,86 - alto (Ilha Bela); PIB

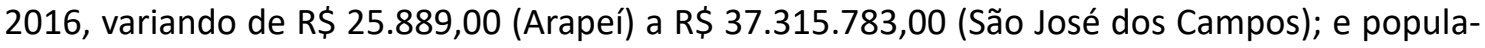
ção 2018, variando de 2.478 habitantes (Arapeí) a 713.943 habitantes (São José dos Campos).

Tabela 1 - Despesa Total e Índices de Despesas TBL do ano de 2019, IFDM 2018, PIB 2016 e População 2018 da RMVPLN

\begin{tabular}{|c|c|c|c|c|c|c|c|}
\hline \multirow[t]{2}{*}{ Município } & \multirow{2}{*}{$\begin{array}{l}\text { Despesa Total }{ }^{1} \\
2019 \text { em R\$ }\end{array}$} & \multicolumn{3}{|c|}{$\begin{array}{l}\text { Despesas com as Dimensões da } \\
\text { Sustentabilidade } 2019 \text { em } \%^{2}\end{array}$} & \multirow{2}{*}{$\begin{array}{c}\text { IFDM } 2018 \\
\text { (ano base } \\
2016)^{3}\end{array}$} & \multirow[t]{2}{*}{ PIB $2016^{4}$} & \multirow{2}{*}{$\begin{array}{l}\text { População } \\
2018^{4}\end{array}$} \\
\hline & & Social & Ambiental & Econômica & & & \\
\hline Aparecida & $134.872 .364,48$ & 52,99 & 0,27 & 8,44 & 0,8084 & 1.115 .003 & 36.129 \\
\hline Arapeí & $16.946 .646,64$ & 61,25 & 8,74 & 5,25 & 0,7321 & 25.889 & 2.478 \\
\hline Areias & $19.567 .229,18$ & 53,63 & 4,30 & 13,77 & 0,6328 & 37.753 & 3.876 \\
\hline Bananal & $35.714 .005,27$ & 66,38 & 6,94 & 0,90 & 0,7191 & 217.166 & 10.896 \\
\hline Caçapava & $266.699 .685,44$ & 53,11 & 1,30 & 12,56 & 0,7788 & 3.580 .187 & 93.488 \\
\hline Cachoeira Paulista & $97.455 .969,01$ & 65,26 & 3,12 & 7,07 & 0,7392 & 559.694 & 33.067 \\
\hline Campos do Jordão & $210.361 .977,96$ & 65,04 & 1,28 & 13,67 & 0,7826 & 1.197.119 & 51.763 \\
\hline Canas & $22.492 .113,56$ & 56,23 & 0,56 & 12,21 & 0,7394 & 150.703 & 5.071 \\
\hline Caraguatatuba & $786.375 .692,56$ & 59,02 & 1,23 & 15,36 & 0,8384 & 2.658 .208 & 119.625 \\
\hline Cruzeiro & $210.537 .900,86$ & 52,27 & 1,70 & 7,40 & 0,7321 & 1.988 .301 & 81.895 \\
\hline Cunha & $66.693 .254,95$ & 59,18 & 2,52 & 14,69 & 0,6739 & 213.621 & 21.639 \\
\hline Guaratinguetá & $360.480 .879,96$ & 54,77 & 1,45 & 12,23 & 0,7814 & 4.232 .993 & 121.073 \\
\hline Igaratá & $41.348 .982,40$ & 62,09 & 0,68 & 15,84 & 0,7112 & 177.756 & 9.483 \\
\hline Ilhabela & $752.499 .193,70$ & 35,38 & 5,91 & 17,30 & 0,8634 & 3.011 .806 & 34.333 \\
\hline Jacareí & $970.418 .337,55$ & 44,78 & 6,03 & 2,19 & 0,7772 & 9.980 .970 & 231.863 \\
\hline Jambeiro & $32.888 .042,19$ & 57,47 & 5,31 & 16,09 & 0,7323 & 274.960 & 6.485 \\
\hline Lagoinha & $19.207 .463,98$ & 64,24 & 1,36 & 12,03 & 0,6999 & 57.554 & 4.903 \\
\hline Lavrinhas & $25.260 .504,19$ & 61,22 & 1,75 & 10,74 & 0,6110 & 104.689 & 7.207 \\
\hline Lorena & 209.077.278,97 & 68,97 & 2,06 & 9,19 & 0,7682 & 2.351 .891 & 88.276 \\
\hline Monteiro Lobato & $17.297 .689,06$ & 61,73 & 1,08 & 13,84 & 0,7189 & 57.846 & 4.608 \\
\hline Natividade da Serra & $27.388 .438,63$ & 50,98 & 3,39 & 19,48 & 0,6728 & 66.404 & 6.681 \\
\hline Paraibuna & $65.568 .209,58$ & 50,63 & 1,52 & 9,45 & 0,7231 & 255.092 & 18.180 \\
\hline Pindamonhangaba & $494.035 .756,14$ & 58,53 & 0,20 & 7,97 & 0,7793 & 6.708 .744 & 166.475 \\
\hline
\end{tabular}


DIMENSÕES DA SUSTENTABILIDADE NOS ORÇAMENTOS MUNICIPAIS

DA REGIÃO METROPOLITANA DO VALE DO PARAÍBA E LITORAL NORTE - SP

Luiz Rodolfo França Pinheiro - Mônica Franchi Carniello - Edson Aparecida de Araujo Querido Oliveira - Adriana Leonidas de Oliveira

\begin{tabular}{lcccccrr|} 
Piquete & $31.760 .060,15$ & 68,36 & 1,90 & 13,88 & 0,6832 & 148.416 & 13.976 \\
\hline Potim & $52.782 .913,28$ & 57,70 & 1,50 & 7,77 & 0,6575 & 187.880 & 24,143 \\
\hline Queluz & $40.609 .741,98$ & 57,07 & 1,60 & 15,96 & 0,6730 & 237.969 & 13.228 \\
\hline Redenção da Serra & $17.068 .469,70$ & 60,51 & 2,56 & 18,15 & 0,7403 & 53.758 & 3.863 \\
\hline Roseira & $37.608 .184,07$ & 67,52 & 0,00 & 13,26 & 0,7871 & 269.309 & 10.621 \\
\hline $\begin{array}{l}\text { Santa Branca } \\
\text { Santo Antônio do }\end{array}$ & $50.356 .380,97$ & 62,01 & 0,76 & 11,11 & 0,6452 & 251.490 & 14.717 \\
Pinhal & $32.819 .654,17$ & 54,86 & 2,44 & 20,03 & 0,7677 & 96.484 & 6.794 \\
$\begin{array}{l}\text { São Bento do } \\
\text { Sapucaí }\end{array}$ & $33.696 .296,42$ & 54,23 & 4,11 & 15,31 & 0,6579 & 178.593 & 10.895 \\
\hline São José do Barreiro & $23.382 .088,52$ & 54,42 & 2,89 & 20,85 & 0,6659 & 48.499 & 4.151 \\
\hline $\begin{array}{l}\text { São José dos } \\
\text { Campos }\end{array}$ & $3.159 .755 .267,60$ & 47,49 & 2,76 & 9,62 & 0,8177 & 37.315 .783 & 713.943 \\
\hline $\begin{array}{l}\text { São Luiz do } \\
\text { Paraitinga }\end{array}$ & $37.123 .669,40$ & 66,57 & 0,65 & 10,25 & 0,6060 & 143.813 & 10.862 \\
\hline São Sebastião & $818.115 .851,73$ & 48,81 & 0,80 & 12,56 & 0,7859 & 3.517 .128 & 87.596 \\
\hline Silveiras & $31.606 .770,70$ & 59,75 & 0,76 & 13,76 & 0,6311 & 63.119 & 6.264 \\
\hline Taubaté & $1.295 .463 .675,04$ & 56,55 & 1,56 & 18,36 & 0,8042 & 14.135 .705 & 311.854 \\
\hline Tremembé & $128.899 .113,83$ & 57,79 & 0,35 & 13,06 & 0,7304 & 656.524 & 46.642 \\
\hline Ubatuba & $366.345 .152,71$ & 56,47 & 5,01 & 6,61 & 0,7803 & 1.786 .358 & 89.747 \\
\hline
\end{tabular}

Fontes: ( $\left.{ }^{1}\right)$ Despesa Total Empenhada Consolidada no Município (TCESP, 2020); $\left({ }^{2}\right)$ dados da pesquisa (2021); $\left({ }^{3}\right)$ baseados em FIRJAN (2020); e ( $\left.{ }^{4}\right)$ Dados EMPLASA, baseados no IBGE (EMPLASA, 2020).

Na Tabela 1, na coluna "Despesas com as Dimensões da Sustentabilidade 2019", notam-se as diferenças percentuais nos gastos com as despesas pagas dos 39 municípios da RMVPLN. Essas informações serão pormenorizadas à frente, mas antecipadamente verifica-se que na dimensão social houve uma variação de 35,38\% (Ilha Bela) a 68,97\% (Lorena), mais de 30 p.p. (pontos percentuais) de diferença; na dimensão econômica variou-se de 0,90\% (Bananal) a 20,85\% (São José do Barreiro), mais de 20 p.p.; e, por fim, na dimensão ambiental, variação de $0,00 \%$ (Roseira) a 8,74\% (Arapeí), mais de 8 p.p.

Nos dados estatísticos da Tabela 2, além de confirmar as variações das dimensões TBL da RMVPLN em 2019, verifica-se também que a Dimensão Social teve uma média percentual de aplicação de despesas pagas, em 2019, de 57,57\%, enquanto que a Econômica 12,26\% e a Ambiental somente 2,36\%. Essas diferenças entre as dimensões TBL devem ser foco dos gestores municipais, pois se constata que os maiores gastos nos municípios estão sendo destinados à Dimensão Social; no entanto, a Dimensão Econômica e a Ambiental, tão importantes na geração de empregos e no cuidado com a qualidade de vida, respectivamente, não podem deixar de receber as devidas atenções desses administradores. Todas essas despesas devem ser mais bem planejadas, distribuídas e executadas pelo PPA, LDO e LOA. 
DIMENSÕES DA SUSTENTABILIDADE NOS ORÇAMENTOS MUNICIPAIS

DA REGIÃO METROPOLITANA DO VALE DO PARAÍBA E LITORAL NORTE - SP

Luiz Rodolfo França Pinheiro - Mônica Franchi Carniello - Edson Aparecida de Araujo Querido Oliveira - Adriana Leonidas de Oliveira

Tabela 2 - Dados Estatísticos das Dimensões TBL da RMVPLN de 2019

\begin{tabular}{c|c|c|c|c}
\hline Dimensão TBL & N & Mínimo & Máximo & Média \\
\hline Social & 39 & 35,38 & 68,97 & 57,57 \\
Econômica & 39 & 0,90 & 20,85 & 12,26 \\
Ambiental & 39 & 0,00 & 8,74 & 2,37 \\
\hline
\end{tabular}

Fonte: Dados da Pesquisa (2021).

\section{Dimensão Social}

Após a divisão em quintis pelo Excel, obteve-se a classificação da Dimensão Social dos 39 municípios da RMVPLN quanto às despesas pagas nos orçamentos relativas à inclusão e/ou assistência social, desporte e lazer, segurança, saúde, educação e cultura. Na Tabela 3 tem-se a divisão das cidades em cinco grupos, suas pontuações de 1 a 5 , a discriminação de quais municípios estão em cada faixa de intervalo e o percentual do município com maior e menor porcentagem em cada intervalo.

Conforme apurado pelos orçamentos municipais, nota-se na Tabela 3 que Ilhabela, a cidade que menos aplica suas despesas na Dimensão Social, possui um índice de, praticamente, a metade da cidade que mais despende seus gastos nessa dimensão, Lorena. Além disso, chama a atenção a posição do maior município da RMVPLN, São José dos Campos, no antepenúltimo lugar ante os 39 municípios.

Tabela 3 - Classificação e Pontuação dos Municípios da RMVPLN, conforme \% das despesas gastas na Dimensão Social em 2019

\begin{tabular}{|c|c|c|}
\hline $\begin{array}{l}\text { Intervalos dos Índices } \\
\text { Dimensão Social }\end{array}$ & $\begin{array}{l}\text { Pontuação } \\
\text { atribuída }\end{array}$ & $\begin{array}{c}\text { Municípios } \\
\text { (ordem decrescente no percentual de despesas pagas) }\end{array}$ \\
\hline $35,38 \mid---53,00$ & 1 & $\begin{array}{l}\text { Aparecida (52,99\%), Cruzeiro, Natividade da Serra, Paraibuna, } \\
\text { São Sebastião, São José dos Campos, Jacareí e Ilhabela }(35,38 \%)\end{array}$ \\
\hline $53,00 \mid---56,48$ & 2 & $\begin{array}{c}\text { Ubatuba (56,47\%), Canas, Santo Antônio do Pinhal, } \\
\text { Guaratinguetá, São José do Barreiro, São Bento do Sapucaí, } \\
\text { Areias e Caçapava }(53,11 \%)\end{array}$ \\
\hline $56,48 \mid---59,19$ & 3 & $\begin{array}{c}\text { Cunha }(59,18 \%) \text {, Caraguatatuba, Pindamonhangaba, Tremembé, } \\
\text { Potim, Jambeiro, Queluz e Taubaté }(56,55 \%)\end{array}$ \\
\hline 59,19|--- 64,25 & 4 & $\begin{array}{l}\text { Lagoinha }(64,24 \%) \text {, Igaratá, Santa Branca, Monteiro Lobato, } \\
\text { Arapeí, Lavrinhas, Redenção da Serra e Silveiras }(59,75 \%)\end{array}$ \\
\hline$>64,25$ & 5 & $\begin{array}{l}\text { Lorena (68,97\%), Piquete, Roseira, São Luiz do Paraitinga, } \\
\text { Bananal, Cachoeira Paulista e Campos do Jordão }(65,04 \%)\end{array}$ \\
\hline
\end{tabular}

Fonte: Dados da Pesquisa (2021)

Ademais da classificação dos cinco grupos na Dimensão Social e de se verificar algumas discrepâncias entre os percentuais gastos pelos municípios, utilizou-se a correlação de Spearman para se verificar a força das relações PIB e População versus Dimensão Social, as quais resultaram em correlações negativas moderada e baixa de -0,330 e -0,264, respectivamente. Já para a relação IFDM versus Dimensão Social, usou-se a correlação de Pearson, que apresentou correlação negativa baixa de $-0,273$. 
Verifica-se pelos índices de correlações apresentados que com o aumento nos indicadores PIB, IFDM e População dos municípios, diminuem as despesas pagas nas peças orçamentárias na RMVPLN destinadas à Dimensão Social.

Com essa análise das correlações, pode-se entender a visão que Sachs (1998) tem sobre a relação entre o crescimento econômico e o desenvolvimento social: quase sempre é enganadora, pois o mau desenvolvimento, a despeito de um PIB per capita elevado, frequentemente ocorre. "Em certos casos, o crescimento econômico pode vir acompanhado de uma involução em termos de desenvolvimento social" (SACHS, 1998, p. 155). Além dessa visão da relação entre crescimento e desenvolvimento econômico, Felix Júnior et al. (2020) trazem a importância da participação popular na definição dos instrumentos orçamentários e seus benefícios para a Dimensão Social. Tal participação pode gerar maior assertividade nas ações públicas voltadas às necessidades sociais da população e ser um caminho para suscitar cidades mais inteligentes e includentes (FELIX JÚNIOR et al., 2020).

\section{Dimensão Econômica}

No tocante aos índices da Dimensão Econômica, a Tabela 4 traz a divisão dos 39 municípios da RMVPLN em cinco grupos, pelos quintis, conforme os resultados apurados quanto às despesas pagas nos orçamentos dos municípios relativas ao turismo, urbanismo (transporte) e desenvolvimento (indústria).

Como pode ser visto na Tabela 4, o índice mais baixo é 0,90\% e os melhores índices acima de 15,97\%. Assim como na Social, a Dimensão Econômica também apresenta grandes discrepâncias entre as porcentagens de aplicação das despesas, com os menores índices apresentando valores praticamente 20 vezes menores que os maiores. Nota-se que Bananal e Jacareí destacam-se negativamente na última e penúltima posição, com índices muitíssimo baixos de despesas. Já as cidades de São José do Barreiro e Santo Antônio do Pinhal são as cidades que mais aplicam gastos nessa dimensão. Destaca-se também a posição de Pindamonhangaba, uma das maiores cidades do Vale do Paraíba, no último grupo, o de pontuação 1, que são os que menos destinam despesas para a dimensão econômica.

Tabela 4 - Classificação e Pontuação dos Municípios da RMVPLN, conforme \% das despesas gastas na Dimensão Econômica em 2019

\begin{tabular}{|c|c|c|}
\hline $\begin{array}{l}\text { Intervalos dos Índices } \\
\text { Dimensão Econômica }\end{array}$ & $\begin{array}{c}\text { Pontuação } \\
\text { atribuída }\end{array}$ & $\begin{array}{c}\text { Municípios } \\
\text { (ordem decrescente no percentual de despesas pagas) }\end{array}$ \\
\hline 0,90|--- 7,98 & 1 & $\begin{array}{c}\text { Pindamonhangaba } \\
(7,97 \%), \text { Potim, Cruzeiro, Cachoeira Paulista, Ubatuba, Arapeí, } \\
\text { Jacareí e Bananal }(0,90 \%)\end{array}$ \\
\hline 7,98|--- 12,04 & 2 & $\begin{array}{c}\text { Lagoinha (12,03\%), Santa Branca, Lavrinhas, São Luiz do } \\
\text { Paraitinga, São José dos Campos, Paraibuna, Lorena e } \\
\text { Aparecida }(8,44 \%)\end{array}$ \\
\hline $12,04 \mid---13,77$ & 3 & $\begin{array}{l}\text { Silveiras (13,76\%), Campos do Jordão, Roseira, Tremembé, } \\
\text { Caçapava, São Sebastião, Guaratinguetá e Canas }(12,21 \%)\end{array}$ \\
\hline 13,77 |--- 15,97 & 4 & $\begin{array}{c}\text { Queluz }(15,96 \%) \text {, Igaratá, Caraguatatuba, São Bento do Sapucaí, } \\
\text { Cunha, Piquete, Monteiro Lobato e Areias }(13,77 \%)\end{array}$ \\
\hline$>15,97$ & 5 & $\begin{array}{c}\text { São José do Barreiro (20,85\%), Santo Antônio do Pinhal, } \\
\text { Natividade da Serra, Taubaté, Redenção da Serra, Ilhabela e } \\
\text { Jambeiro }(16,09 \%)\end{array}$ \\
\hline & & e: Dados da Pesquisa (2021) \\
\hline
\end{tabular}


Testes de correlação também foram utilizados para se verificar o comportamento das despesas pagas na Dimensão Econômica ante os índices PIB, IFDM e População dos municípios. Da mesma maneira, utilizou-se a correlação de Spearman para se verificar a força das relações PIB e População versus Dimensão Econômica, ambas resultando em correlações negativas baixas de $-0,268$ e - 0,254 , respectivamente. Já para a relação IFDM versus Dimensão Social, usou-se a correlação de Pearson, que apresentou correlação negativa baixa de -0,061.

Essas correlações também sugerem, assim como na Dimensão Social, que com o aumento nos indicadores PIB, IFDM e População dos municípios, diminuem as despesas pagas nos orçamentos dos municípios da RMVPLN destinadas à Dimensão Econômica.

A preocupação que surge dessa análise é a que Sachs demonstra ao dizer que não se pode "reduzir o desenvolvimento apenas ao crescimento econômico. Devemos usar duas ópticas simultâneas: de um lado, o enfoque pelo crescimento, que nos remete ao crescimento do PIB, [...] e, de outro, o enfoque que [...] favorece a inserção social pelo trabalho decente de todos [...]" (SACHS, 2010, p. 33).

Pechenskaya-Polishchuk (2020) também assinala que a solução para que uma gestão econômica possa ser revertida em políticas sociais adequadas à população de uma região, é necessário que recursos, condições particulares características dos territórios, necessidades e interesses das pessoas sejam direcionados por uma gestão pública eficaz.

Assim, se os indicadores estão melhorando e as despesas da dimensão econômica estão diminuindo, a relação sugere uma menor preocupação dos gestores municipais com a geração de emprego e renda aos munícipes.

\section{Dimensão Ambiental}

A classificação dos municípios da RMVPLN segundo os índices apurados da Dimensão Ambiental, por meio dos quintis, levou em consideração as despesas pagas dos municípios relativas à gestão ambiental e saneamento.

Como pode ser visto na Tabela 5, o índice mais baixo é 0,00\% apresentado pela cidade de Roseira, ou seja, em seu orçamento não há nenhuma despesa paga relacionada à Dimensão Ambiental. Além disso, os maiores índices apresentam-se acima de 4,12\%, o que demonstra, além das desigualdades dos índices entre os municípios, uma baixa aplicação de recursos públicos nessa dimensão.

$\mathrm{Na}$ Tabela 5, conforme apurado pelos orçamentos municipais, nota-se, novamente, um destaque negativo de Pindamonhangaba, na penúltima posição das despesas gastas nessa dimensão; e, como destaque positivo, duas cidades do chamado "Vale Histórico", Arapeí e Bananal, na primeira e segunda posição, respectivamente. 
DIMENSÕES DA SUSTENTABILIDADE NOS ORÇAMENTOS MUNICIPAIS

DA REGIÃO METROPOLITANA DO VALE DO PARAÍBA E LITORAL NORTE - SP

Luiz Rodolfo França Pinheiro - Mônica Franchi Carniello - Edson Aparecida de Araujo Querido Oliveira - Adriana Leonidas de Oliveira

Tabela 5 - Classificação e Pontuação dos Municípios da RMVPLN, conforme \% das despesas gastas na Dimensão Ambiental em 2019

\begin{tabular}{|c|c|c|}
\hline $\begin{array}{l}\text { Intervalos dos Índices } \\
\text { Dimensão Ambiental }\end{array}$ & $\begin{array}{l}\text { Pontuação } \\
\text { atribuída }\end{array}$ & $\begin{array}{c}\text { Municípios } \\
\text { (ordem decrescente no percentual de despesas pagas) }\end{array}$ \\
\hline 0,00 |--- 0,77 & 1 & $\begin{array}{c}\text { Santa Branca }(0,76) \text {, Silveiras, Igaratá, São Luiz do Paraitinga, } \\
\text { Canas, Tremembé, Aparecida, Pindamonhangaba e Roseira } \\
(0,00 \%)\end{array}$ \\
\hline 0,77|--- 1,46 & 2 & $\begin{array}{c}\text { Guaratinguetá (1,45\%), Lagoinha, Caçapava, Campos do Jordão, } \\
\text { Caraguatatuba, Monteiro Lobato e São Sebastião (0,80\%) }\end{array}$ \\
\hline 1,46|--- 2,07 & 3 & $\begin{array}{c}\text { Lorena }(2,06 \%) \text {, Piquete, Lavrinhas, Cruzeiro, Queluz, Taubaté, } \\
\text { Paraibuna e Potim }(1,50 \%)\end{array}$ \\
\hline 2,07|--- 4,12 & 4 & $\begin{array}{l}\text { São Bento do Sapucaí (4,11\%), Natividade da Serra, Cachoeira } \\
\text { Paulista, São José do Barreiro, São José dos Campos, Redenção } \\
\text { da Serra, Cunha e Santo Antônio do Pinhal (2,44\%) }\end{array}$ \\
\hline$>4,12$ & 5 & $\begin{array}{l}\text { Arapeí }(8,74 \%) \text {, Bananal, Jacareí, Ilhabela, Jambeiro, Ubatuba e } \\
\text { Areias }(4,30 \%)\end{array}$ \\
\hline
\end{tabular}

Verificou-se também o comportamento da Dimensão Ambiental quando comparada aos indicadores PIB 2016, IFDM 2018 (ano-base 2016) e População (2018), utilizando-se, para esta dimensão, somente a correlação de Spearman. Todos os resultados para as relações PIB, IFDM e População versus Dimensão Ambiental resultaram em correlações negativas baixas de valores $-0,120,-0,064$ e - 0,109 , respectivamente.

Na mesma linha dos resultados dos comportamentos das outras dimensões, verificou-se que com o aumento nos indicadores PIB, IFDM e População dos municípios, diminuem-se também as despesas pagas nas peças orçamentárias na RMVPLN destinadas à questão ambiental.

Analisando-se estes resultados, identifica-se que o desenvolvimento regional ambientalmente sustentável deve ser buscado constantemente, indo ao encontro do que Sachs explica sobre o termo sustainable, conceito que para o autor traz um olhar ao "desenvolvimento em harmonia com a natureza em vez de crescimento fundamentado na apropriação predadora dos recursos, menosprezando as externalidades negativas constituídas pelos malefícios resultantes da produção e do consumo" (SACHS, 1988, p. 164).

Sargany et al. (2020) trazem um alerta que para se obter bons índices de sustentabilidade requer-se criatividade, compromisso com a conservação da natureza e uma cultura socioeconômica alinhada a uma consciência local da dinâmica ambiental atual. Assim, há necessidade de que os munícipes da RMVPLN cobrem de seus gestores políticas públicas sempre voltadas a um crescimento econômico sustentável.

\section{Resultado Agregado das Três Dimensões da Sustentabilidade (TBL)}

Após a classificação de todos os 39 municípios em cada dimensão TBL, realizou-se o somatório de suas pontuações e voltou-se a classificá-los pelos quintis. Dessa maneira, restou apurado, conforme Tabela 6, que há municípios com menos de um terço da pontuação dos mais bem classificados. Outro ponto a ressaltar é que esta classificação foi realizada por meio do software Excel, como já mencionado no método. O Excel não divide em cinco partes iguais, mas em proporcionais, conforme fórmula já explicitada. Assim, por este motivo e tendo em vista 
uma série de pontuações iguais, houve, por exemplo, somente 3 municípios selecionados como altamente sustentáveis e 13 como insustentáveis.

Da Tabela 6 destacam-se os três únicos municípios com desempenho altamente sustentável, Jambeiro, Redenção da Serra e Piquete. A única cidade grande da RMVPLN que figura entre os municípios muito sustentáveis é Taubaté, com 11 pontos na classificação. Já entre as cidades que constam como insustentáveis, há as cidades de São José dos Campos, Jacareí e Pindamonhangaba, grandes municípios da região. No geral, verifica-se que a região possui mais de $56 \%$ de seus municípios com desempenho sustentável ou maior; $10 \%$, em adequação e $34 \%$ insustentáveis, necessitando rever seus gastos municipais.

Tabela 6 - Pontuação Agregada dos Municípios e Classificação Quanto à Sustentabilidade TBL na RMVPLN em 2019

\begin{tabular}{|c|c|c|c|c|c|}
\hline Município & $\begin{array}{c}\text { Pontuação } \\
\text { Dimensão } \\
\text { Social }\end{array}$ & $\begin{array}{l}\text { Pontuação } \\
\text { Dimensão } \\
\text { Econômica }\end{array}$ & $\begin{array}{l}\text { Pontuação } \\
\text { Dimensão } \\
\text { Ambiental }\end{array}$ & $\begin{array}{l}\text { Pontuação } \\
\text { Agregada }\end{array}$ & $\begin{array}{l}\text { Desempenho } \\
\text { Sustentabilidade TBL }\end{array}$ \\
\hline Jambeiro & 3 & 5 & 5 & 13 & Altamente Sustentável \\
\hline Redenção da Serra & 4 & 5 & 4 & 13 & Altamente Sustentável \\
\hline Piquete & 5 & 4 & 3 & 12 & Altamente Sustentável \\
\hline Areias & 2 & 4 & 5 & 11 & Muito Sustentável \\
\hline Bananal & 5 & 1 & 5 & 11 & Muito Sustentável \\
\hline Cunha & 3 & 4 & 4 & 11 & Muito Sustentável \\
\hline Ilhabela & 1 & 5 & 5 & 11 & Muito Sustentável \\
\hline Santo Antônio do Pinhal & 2 & 5 & 4 & 11 & Muito Sustentável \\
\hline São José do Barreiro & 2 & 5 & 4 & 11 & Muito Sustentável \\
\hline Taubaté & 3 & 5 & 3 & 11 & Muito Sustentável \\
\hline Arapeí & 4 & 1 & 5 & 10 & Sustentável \\
\hline Cachoeira Paulista & 5 & 1 & 4 & 10 & Sustentável \\
\hline Campos do Jordão & 5 & 3 & 2 & 10 & Sustentável \\
\hline Lorena & 5 & 2 & 3 & 10 & Sustentável \\
\hline Monteiro Lobato & 4 & 4 & 2 & 10 & Sustentável \\
\hline Natividade da Serra & 1 & 5 & 4 & 10 & Sustentável \\
\hline Queluz & 3 & 4 & 3 & 10 & Sustentável \\
\hline São Bento do Sapucaí & 2 & 4 & 4 & 10 & Sustentável \\
\hline Caraguatatuba & 3 & 4 & 2 & 9 & Sustentável \\
\hline Igaratá & 4 & 4 & 1 & 9 & Sustentável \\
\hline Lavrinhas & 4 & 2 & 3 & 9 & Sustentável \\
\hline Roseira & 5 & 3 & 1 & 9 & Sustentável \\
\hline Lagoinha & 4 & 2 & 2 & 8 & Em adequação \\
\hline São Luiz do Paraitinga & 5 & 2 & 1 & 8 & Em adequação \\
\hline Silveiras & 4 & 3 & 1 & 8 & Em adequação \\
\hline Ubatuba & 2 & 1 & 5 & 8 & Em adequação \\
\hline Caçapava & 2 & 3 & 2 & 7 & Insustentável \\
\hline Guaratinguetá & 2 & 3 & 2 & 7 & Insustentável \\
\hline Jacareí & 1 & 1 & 5 & 7 & Insustentável \\
\hline Potim & 3 & 1 & 3 & 7 & Insustentável \\
\hline
\end{tabular}




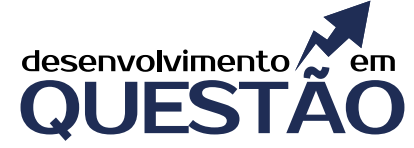

DIMENSÕES DA SUSTENTABILIDADE NOS ORÇAMENTOS MUNICIPAIS

DA REGIÃO METROPOLITANA DO VALE DO PARAÍBA E LITORAL NORTE - SP

Luiz Rodolfo França Pinheiro - Mônica Franchi Carniello - Edson Aparecida de Araujo Querido Oliveira - Adriana Leonidas de Oliveira

$\begin{array}{llllll}\text { Santa Branca } & 4 & 2 & 1 & 7 & \text { Insustentável } \\ \text { São José dos Campos } & 1 & 2 & 4 & 7 & \text { Insustentável } \\ \text { Tremembé } & 3 & 3 & 1 & 7 & \text { Insustentável } \\ \text { Canas } & 2 & 3 & 1 & 6 & \text { Insustentável } \\ \text { Paraibuna } & 1 & 2 & 3 & 6 & \text { Insustentável } \\ \text { São Sebastião } & 1 & 3 & 2 & 6 & \text { Insustentável } \\ \text { Cruzeiro } & 1 & 1 & 3 & 5 & \text { Insustentável } \\ \text { Pindamonhangaba } & 3 & 1 & 1 & 5 & \text { Insustentável } \\ \text { Aparecida } & 1 & 2 & 1 & 4 & \text { Insustentável }\end{array}$

$\mathrm{Na}$ análise do comportamento da Sustentabilidade TBL versus PIB 2016, IFDM 2018 (ano base 2016) e População (2018), trabalhou-se com os testes de correlação de Spearman e de Pearson. Utilizou-se Spearman para a verificação da força das relações PIB e População versus Sustentabilidade TBL, as quais resultaram em correlação negativa moderada de $-0,409$ e $-0,373$, respectivamente; e Pearson para a relação IFDM versus Sustentabilidade TBL, que apresentou correlação negativa baixa de -0,161.

Desta forma, ao se analisar os índices de correlação encontrados, tem-se que conforme aumentam o PIB, o IFDM e a População, as despesas dos orçamentos públicos municipais com Sustentabilidade TBL da RMVPLN diminuem.

Essa análise traz à tona o que Sachs $(2010$, p. 32) diz do papel do Estado (e aqui se incluem os governos municipais) e sua capacidade de regular, naquilo que lhe compete, a dimensão econômica para "mantê-la no caminho do desenvolvimento socialmente inclusivo e benigno do ponto de vista ambiental". Compreender a Sustentabilidade TBL é reconhecer, desenvolver e explorar oportunidades pelos indivíduos para fornecer benefícios econômicos, sociais e ecológicos para bens e serviços futuros de uma região (SARGANY et al., 2020).

Há de se aproveitar as melhorias nos indicadores PIB e IFDM, para melhorar, também, a aplicação das despesas com a sustentabilidade TBL e, consequentemente, trazer um maior desenvolvimento à RMVPLN.

\section{CONCLUSÃO}

Esta pesquisa baseou-se em verificar como o dinheiro público está sendo gasto pelos municípios da RMVPLN de São Paulo nas dimensões TBL da Sustentabilidade, objetivo que foi plenamente atingido com o levantamento das informações apresentadas. Entende-se, também, que a lacuna quanto ao comportamento dos indicadores PIB, IFDM e população dos municípios da região em relação às destinações orçamentárias para a Sustentabilidade TBL foi preenchida e pode proporcionar uma nova perspectiva tanto para os gestores quanto para os munícipes da região.

Em relação aos resultados obtidos na pesquisa, percebeu-se, primeiramente, uma grande disparidade tanto dentro de cada dimensão da Sustentabilidade quanto em uma análise comparativa das médias de despesas pagas entre as dimensões, a saber, 57,57\% na Dimensão Social, $12,26 \%$ na Econômica e 2,36\% na Ambiental. Esses dados mostram que uma distribuição mais equitativa entre as dimensões pode ser um caminho para o fortalecimento de um desenvolvimento sustentável com excelentes retornos a toda a RMVPLN. 
Quanto aos índices dos municípios em cada dimensão em separado, constatou-se uma grande variação entre os que mais aplicam e os que menos aplicam recursos e que grandes municípios da Região têm baixas destinações nessas três dimensões. Já na análise do comportamento do resultado agregado das dimensões TBL da Sustentabilidade, restou apurado no ano de 2019 que quanto maiores os indicadores PIB, IFDM e População dos municípios da RMVPLN, menores são as despesas pagas nos orçamentos destinadas à Sustentabilidade. Percebe-se que a RMVPLN possui bons indicadores no geral, mas gestores e a participação popular na elaboração de orçamentos municipais ainda são fatores importantes para que o dinheiro público tenha destinação cada vez mais acertada.

Concluindo, todos esses resultados apontam para a importância que o trabalho dos gestores públicos tem no planejamento e na execução dos orçamentos municipais, seja em uma melhor equalização da aplicação efetiva das despesas entre as dimensões sustentáveis (TBL), seja em uma publicidade mais eficiente e eficaz desses gastos, pois além da relevância de uma competente aplicação das despesas, é vital uma correta informação quanto à destinação real de onde os recursos estão sendo aplicados.

Finalmente, recomenda-se que esta pesquisa seja continuada com análises futuras nos próximos exercícios financeiros ou mesmo na comparação com anos anteriores para que possa ser gerada uma série histórica desses índices.

\section{REFERÊNCIAS}

AGRAWALA, S.; SINGHB, R. K. Analyzing disposition decisions for sustainable reverse logistics: Triple Bottom Line approach. Resources, Conservation \& Recycling, v. 150, n. 104.448, p. 1-11, 2019.

BRASIL. Lei no 10.257, de 10 de julho de 2001. Regulamenta os arts. 182 e 183 da Constituição Federal, estabelece diretrizes gerais da política urbana e dá outras providências. Brasília, DF: Presidência da República, 2001. Disponível em: http://www.planalto.gov.br/ccivil_03/leis/leis_2001/l10257.htm. Acesso em: 13 maio 2020.

BRASIL. Ministério da Economia. Manual Técnico de Orçamento (MTO). Brasília: ME, 2020. Disponível em: https://www1.siop.planejamento.gov.br/mto/lib/exe/fetch.php/mto2020:mto2020-versao11.pdf. Acesso em: 13 maio 2020.

CEPAM. Fundação Prefeito Faria Lima - Centro de Estudos e Administração Municipal. Plano Diretor passo a passo. Coordenação Mariana Moreira. São Paulo: Cepam, 2005.

CRESWELL, J. W. Projeto de pesquisa: métodos qualitativo, quantitativo e misto. Tradução Luciana de Oliveira da Rocha. 2. ed. Porto Alegre: Artmed, 2007.

DALEVSKA, N. et al. A model for estimating social and economic indicators of sustainable development. Entrepreneurship and Sustainability Issues, v. 6, n. 4, p. 1.839-1.860, 2019.

DALLABRIDA, V. R. Economia, cultura e desenvolvimento: uma primeira aproximação sobre as origens teóricas da abordagem do tema. Revista Brasileira de Gestão e Desenvolvimento Regional (G\&DR), v. 7, n. 2, p. 282-299, 2011.

ELKINGTON, J. Cannibals With Forks: The Triple Bottom Line of 21st Century Business. Capstone: Oxford, 1997.

EMPLASA. Empresa Paulista de Planejamento Metropolitano S/A. Região Metropolitana do Vale do Paraíba e Litoral Norte. Disponível em: https://emplasa.sp.gov.br/RMVPLN. Acesso em: 14 maio 2020.

FIRJAN. Federação das Indústrias do Estado do Rio de Janeiro. Índice Firjan de Desenvolvimento Municipal (IFDM). Disponível em: https://www.firjan.com.br/ifdm/consulta-ao-indice/ifdm-indice-firjan-de-desenvolvimento-municipal-resultado.htm $\mathrm{U} U \mathrm{~F}=\mathrm{SP} \& \mathrm{IdCidade}=353800 \&$ Indicador $=1 \& A n o=2016$. Acesso em: 2 maio 2020.

FELIX JÚNIOR, L. A. et al. Social participation in the definition of budgetary instruments. Transforming Government: People, Process and Policy, v. 14, n. 5, p. 737-755, 2020.

FIELD, A. Descobrindo a estatística usando o SPSS. Tradução Lorí Viali. 2. ed. Porto Alegre: Artmed, 2009. 
FUZARO, P. A.; CARNIELLO, M. F. Estudo comparativo do índice de desenvolvimento humano municipal e Índice Firjan de Desenvolvimento Municipal na Região Metropolitana do Vale do Paraíba-SP. Desenvolvimento em Questão, v. 16, n. 45, p. 75-100, 2020.

GOMES, W. O.; VIEIRA, E. T. A sustentabilidade do desenvolvimento na Região Metropolitana do Vale do Paraíba e Litoral Norte: análise das variáveis da Lei de Responsabilidade Fiscal e do Desenvolvimento Social Municipal. Gestão e Desenvolvimento em Revista, v. 4, n. 1, p. 97-114, 2018.

GU, W. et al. Entrepreneurship and high-quality economic development: based on the triple bottom line of sustainable development. International Entrepreneurship and Management Journal, v. 17, p. 1-27, 2021.

HAMMER, J.; PIVO, G. The Triple Bottom Line and Sustainable Economic Development Theory and Practice. Economic Development Quarterly, v. 31, n. 1, p. 25-36, 2017.

IBGC. Instituto Brasileiro de Governança Corporativa. Código das melhores práticas de governança corporativa. São Paulo: IBGC, 2015.

JEURISSEN, Ronald. Cannibals With Forks: The Triple Bottom Line of 21st Century Business. Journal of Business Ethics, v. 23, p. 229-231, 2000. [Section] Book Reviews. Book Reviews of: ELKINGTON, John. Cannibals With Forks: The Triple Bottom Line of 21st Century Business. Capstone, Oxford, 1997, 402 p.

LONGONI, A.; CAGLIANO, R. Sustainable Innovativeness and the Triple Bottom Line: The Role of Organizational Time Perspective. Journal of Business Ethics, Springer, v. 151, n. 4, p. 1.097-1.120, 2016.

OLIVEIRA, E. A. A. Q.; QUINTAIROS, P. C. R. Estudo das disparidades econômicas e tecnológicas no desenvolvimento regional desequilibrado do Vale do Paraíba. Revista Brasileira de Gestão e Desenvolvimento Regional (G\&DR), v. 7, n. 2, p. 256-281, 2011.

OLIVEIRA, M. L. Desenvolvimento sustentável e os municípios: uma análise sob a perspectiva dos objetivos do desenvolvimento sustentável e da Lei no 13.493/17 (PIV - Produto Interno Verde). Revista de Direito e Sustentabilidade, v. 4, n. 1, p. 59-76, 2018.

PECHENSKAYA-POLISHCHUK, M. A. Instruments and principles of reallocating budgetary resources in the region. Economic and Social Changes: Facts, Trends, Forecast, v. 13, n. 2, p. 71-88, 2020.

PINHEIRO, W. G.; VIEIRA, E. T.; OLIVEIRA, E. A. A. Q. As relações entre o Índice de Gini com o Índice de Desenvolvimento Humano e o Produto Interno Bruto dos municípios da RMVPLN sob a ótica do desenvolvimento regional. Revista Humanidades e Inovação, v. 6, n. 12, p. 43-66, 2019.

PRODANOV, C. C.; FREITAS, E. C. Metodologia do trabalho científico: métodos e técnicas da pesquisa e do trabalho acadêmico. 2. ed. Novo Hamburgo: Feevale, 2013.

SACHS, I. Barricadas de ontem, campos de futuro. Estudos Avançados, v. 24, n. 68, p. 25-38, 2010.

SACHS, I. Desenvolvimento, direitos humanos e cidadania. In: PINHEIRO, P. S.; GUIMARÃES, S. P. (org.). Direitos humanos no século XXI. Brasília: Instituto de Pesquisa de Relações Internacionais (Irpi); Fundação Alexandre de Gusmão, 1988.

SACHS, I. O desenvolvimento enquanto apropriação dos direitos humanos. Estudos Avançados, v. 12, n. 33, p. 149-156, 1998.

SANTOS, I. C.; OLIVEIRA, A. L.; MORAIS, P. R. Os atributos de um bom trabalho monográfico: reflexões e direcionamentos. Revista UniVap, v. 16, n. 28, p. 20-28, 2010.

SÃO PAULO (SP). Lei Complementar no 1.166, de 9 de janeiro de 2012. Cria a região metropolitana do Vale do Paraíba e Litoral Norte, e dá providências correlatas. São Paulo: Governo do Estado, 2012. Disponível em: http://www.al.sp.gov.br/repositorio/legislacao/lei.complementar/2012/lei.complementar-1166-09.01.2012.html. Acesso em: 18 maio 2020.

SARGANI, G. R. et al. Sustainable Entrepreneurship in the Agriculture Sector: The Nexus of the Triple Bottom Line Measurement Approach. Sustainability, v. 12, p. 1-24, 2020.

SILVA, E. L.; MENEZES, E. M. Metodologia da pesquisa e elaboração de dissertação. 4. ed. Florianópolis: UFSC, 2005.

TCESP. Tribunal de Contas do Estado de São Paulo. Transparência municipal TCESP. Disponível em: https://transparencia.tce.sp.gov.br/. Acesso em: 16 abr. 2020.

WISE, N. Outlining triple bottom line contexts in urban tourism regeneration. Cities, v. 53, p. 30-34, 2016. 